\title{
The Impact of Relational Governance on Performance Improvement in Export Manufacturing Firms
}

\author{
Usama Awan $^{1}$ (D), Andrzej Kraslawski ${ }^{1,2}$ (D) Janne Huiskonen ${ }^{1}$ \\ ${ }^{1}$ LUT School of Business and Management, Industrial Engineering and Management, Lappeenranta University of Technology (Finland) \\ ${ }^{2}$ Department of Process and Environmental Engineering, Lod₹ University of Technology (Poland) \\ usama.awan@lut.fi,.Andrzej.Kraslawski@lut.fi,Janne.Huiskonen@lut.fi
}

Received: December 2017

Accepted: February 2018

\section{Abstract:}

Purpose: This paper seeks to identify the factors affecting social performance improvements in the Pakistan export manufacturing firms and investigate inter-relationships existing among them.

Design/methodology/approach: This study used a cross-sectional survey; data were collected using self-administered survey questionnaire. Using data collected from 239 small- and medium-sized direct exporters manufacturing firms in Pakistan. We used structural equation modelling (SEM) approach to test structural model, and mediation analysis was conducted with regression analysis.

Findings: The results support that meta-cognitive dimensions of cultural intelligence effect on social performance improvements, while the social performance improvement significant associated with innovation performance improvements. We suggest that cultural intelligence is a key to maintaining a relationship through development better cultural understanding and creating harmony among suppliers and buyers through minimizing the differences and disputes, requires developing social cohesion. Our results reveal that exporting firms need to adapt, reconfigure cultural knowledge and integrate resources into the operations to build learning capability, in turn, they can improve social performance and achieve superior innovation performance.

Practical implications: Through the application of cultural intelligence capability, a firm could increase its ability to sense cultural differences, seize and adapt globally scattered cultural practices on social issues and allows for the development of unique knowledge resources and capabilities, impact on firm social performance and innovation performance improvements.

Originality/value: The study conducted in Pakistan cultural context, which can be extended to other Asian countries. We argue that in a globalising world it is pertinent for exporting firms to have a better understanding of the various facets of cultural when dealing with inter-organisational relationships.

Keywords: relational governance, cultural intelligence, social performance, innovation performance improvement, manufacturing firms

\section{Introduction}

The supply chain relationship caused by cultural differences is now a challenge for supply chain management. Crosscultural interaction is inevitable between supply chain partners to deal with the disputes, and ways to handle and understand different beliefs and expectations. The innovation performance implications in export and importer relationship are gaining scholarly attention in international business research. Relational governance may 
significantly impact on innovation performance improvements (Awan, 2018). As an increasing number of firms are dealing with buyers and suppliers abroad, cultural differences create misunderstanding within the inter-organisational relationship that can result in a false reading of partner's behaviour (Ribbink \& Grimm, 2014). The current discussion on governance of inter-firm relationships calls for research on "how" governance influences outcomes (Cao \& Lumineau, 2015). This study responds to the increase in recent calls to understand the impact of culture on firm performance outcomes through governance mechanism (Handley \& Angst, 2015). Recently, (Awan, Kraslawski \& Huiskonen, 2018a) found that the supplier-buyer engagement in a supply chain is essential for the adoption and diffusion of new sustainability practices and Cultural intelligence is at the heart of the socially sustainable development processes. The present study investigates the question, whether the use of cultural capabilities by export manufacturing firm's are effective in bringing the improvement of the firm performance. Furthermore, (Bstieler \& Hemmert, 2015) proposed a conceptual framework how manufacturing firm in Asia can achieve coordination with their foreign partner. According to (López-Duarte, González-Loureiro, Vidal-Suárez \& González-Diaz, 2016) cultural differences among the distant partners tend to hamper collaboration, the establishment of process and procedure that encourage information flow. Despite the crucial role governance mechanism plays in firm performance improvements, the extant research mostly focuses on the operational and relationship performance (Paulraj, Jayaraman \& Blome, 2014).

Relational governance emphasises the role of repeated interactions which lead to mutual understanding, social identification, and trust (Das \& Teng, 1998). Prior research in operations management literature has examined organisational culture at individual partnership context in a single industry evaluated its effect on firm manufacturing practices and performance (Naor, Linderman \& Schroeder, 2010). Whereas, more recent studies emphasise on improving innovation performance through environmental practices (Macchion, Moretto, Caniato, Caridi, Danese, Spina et al., 2017). In the era of globalisation, supply chains play a fundamental role in the development of an organisation and its goal of profit maximization (Tavana, Amin, Di \& Rahpeyma, 2016). Given the importance of being successful in coordination in an international context, many scholars have argued that it is vital to possess cultural knowledge and skills in cross-culture interactions (Charoensukmongkol, 2016). Further, (Awan, Kraslawsk \& Huiskonen, 2018b) suggest that cultural intelligence capability is a tool that enables individual effectively interact with and learn from their buyers can overcome dualities of decision-making and help to foster sustainability commitment. Moreover, Gonçalves, Reis, Sousa, Santos, Orgambídez-Ramos and Scott (2016) emphasize the importance of cultural intelligence promotes a more effective conflict management style and therefore contributing to organisational success.

A prior study (Molinsky, 2007) has observed that employees with a better cultural understanding of other partners can benefit to enhance knowledge exchange. While some scholars have started examining the implications of culture on governance mechanism (Handley \& Angst, 2015), there is still little research that explores the various aspects of culture and how firm deal with it. Specifically, exporting firms from emerging countries tend to have limited resource (Adu-Gyamfi \& Korneliussen, 2013). It thus becomes possible for firms to learn to form each other and benefit from mutual learning in a way that creates new value (Tan, Wong \& Chung, 2016).

The ample research on governing inter-firm supply chain relationship and innovation performance improvement has yet to yield a uniform conclusion in the light of diverse perspective and cultural differences on the nature of cooperation and its performance contributions. In today's culturally diverse customers and successful international business transactions, effective work interaction with multi-cultural customers requires an understanding of differences in behaviours, perspectives, and motivation and communication styles. For successful international business transactions, one has to go beyond the ethnocentric worldview and develop a global mindset' (Christiansen, 2015). Pakistan has a higher power distance culture, where decision-making and communication style is informal. This study has responded to research call (Molinsky, 2007), by exploring the role of supplier firm cultural intelligence to enhance more coordination for social performance improvement and innovation performance improvements. While the research on cultural intelligence is developing, so far few study has explicitly investigated culture's influence on governance mechanism. The role of cultural intelligence (CQ) has not been examined at the level of governance mechanism an important gap exists and offer a useful venue within the operations management literature. Moreover, little is known about how social performance improvement mediates between the relational 
governance and innovation performance improvements. Empirical research provides us with little understanding of how different integration efforts and approaches influence on firm performance.

The present study strives to expand research by answering the research questions, (1) What is the relationship between relational governance and firm social performance and innovation performance improvements? (2) Do cognitive and meta-cognitive cultural intelligence capabilities mediates the relationship between relational governance social performance improvement and innovation performance improvements? Our conceptual framework (Figure 1 ) is grounded in the resource-based view (RBV). We draw our conceptual framework on theories that have used in previous research studies in Buyer-supplier relationships. According to the RBV theory resources are heterogeneous and immobile (Hunt \& Morgan, 1995). As a result, organizations establish relationships to access resources and enhance their competitive advantage. Such relational capabilities can be rare, inimitable and substitutable at a company level (Matanda \& Freeman, 2009). The present study makes two important contributions to both theory and practice. First, we contribute to the literature by highlighting the role of cultural adaptation as a prerequisite for the operations managers in export manufacturing firms. Second, our findings lend support to the important role of cultural intelligence two factors, cognitive and meta-cognitive factors influencing social performance improvements and innovation performance improvements.

\section{Literature Review}

\subsection{Theoretical View}

The resource-based view (RBV) of the firm is one of the most widely accepted theoretical frameworks, proposing that organisational capabilities can be important in shaping firm success in the market (Barney \& Felin, 2013). Recent RBV research has called for a better understanding of how resources and capabilities are deployed to capture performance benefits (Sirmon, Hitt \& Ireland, 2007). Previous studies focused on the different factor of organisational capabilities, such as learning, emotional, technological to improve the performance. Few studies have demonstrated the cultural aspects of firm-specific capabilities and the impact on performance (Moon, 2010). The development of learning capabilities requires integration of resources. However, CQ capability is another organisational capability that over time make distinctive, embedded a source of competitive. According to (Moon, 2010), it demonstrates organisation's capability to reconfigure and adapt its competency to rapidly changing the intercultural environment.

Social performance aspects in the supply chain of manufacturing firms are less emphasised (Brandenburg, Govindan, Sarkis \& Seuring, 2014; Husgafvel, Pajunen, Virtanen, Paavola, Päällysaho, Inkinen et al., 2015). Social issues in the supply chain such as health and safety, bonded child labour and worker job environment have an impact on firm social performance (Mani, Agrawal \& Sharma, 2015). Managing and identifying the environmental impact on human life through Supply chain research receiving attention in operations management Chiou, Chan, Lettice and Chung (2011). Lee, Klassen, Furlan and Vinelli (2014) highlighted the importance of investigating how different social supply chain practices have affected the firm sustainability performance in Asian countries. There is growing trend towards developing a more sustainable way of managing social performance among the manufacturing firms (Husgafvel et al., 2015).

Cultural intelligence defined as "A person's capability for successful adaptation to new cultural settings; that is, for unfamiliar settings attributable to cultural context" (Earley \& Ang, 2003). Similarly (Peterson, 2011) found CQ as "the aptitude to use skills and abilities appropriately in cross-culture environment". In line with this (Eisenberg, Lee, Brück, Brenner, Claes, Mironski et al., 2013), whose definition we followed in our present study, stating that cultural intelligence (CQ), reflects capabilities to manage oneself effectively and to interact and harmonise with others in cross-cultural landscapes (Eisenberg et al., 2013). Metacognitive and cognitive facets of cultural intelligence (CQ) deal with information processing aspects of intelligence, which closely linked to mental capability of processing to acquire, cultural knowledge and reflects the specific knowledge of content in the culturally diverse situation. This process is concerned with structure and procedures facilitating coordination and integration in a cross-cultural context (Moon, 2010). According to (Moon, 2010), organisational CQ capability framework consists of cross-cultural coordination, cross-cultural learning, and cross-cultural reconfiguration. The literature suggests that firm develop process and reconfiguration capability is embedded in coordination and sharing and processing of 
knowledge and information (Teece \& Pisano 2004). Organisational collaborative culture effects on the core competencies and essential for the sustainable growth of the firm (Awan, Muneer \& Abbas, 2013).

\subsection{Hypothesis Development}

Much research has attempted to explain the effects of relational governance structure on performance, but few studies have incorporated strategic consideration the role of culture in managing interfirm relationship (Handley \& Angst, 2015). According to (Poppo \& Zenger, 2002), relational governance enforces of promise, obligations, expectations through social process that promotes norms of flexibility, solidarity and adaptations. In this present study, relational governance is based on the joint problem solving and collaboration. However, in many buyersupplier relationships, a natural way of doing business is work jointly through relational governance (Zhou, Zhang, Sheng, Xie \& Bao, 2014). This supports the notion that firm deploys relational governance is useful in knowledge acquisition (Zhou et al., 2014). Collaboration and assessment with social performance, measure social performance of buying firm (Golini, Longoni \& Cagliano, 2014; Gualandris, Golini \& Kalchschmidt, 2014). Relational governance refers to the extent to which relationship between the parties are governed by shared norms and social mechanism (Liu, Luo \& Liu, 2009). Relational governance is a necessary component of firm performance (Schepker, Oh, Martynov \& Poppo, 2014). Governance mechanisms are essentially important for the stability of the supplier relationship, and it refers to a structural mechanism through which both parties behave with the aim of achieving the joint objectives (Cao \& Lumineau, 2015; Liu et al., 2009).

Recently (Awan \& Kraslawski, 2017), examines the way in which supplier firm perceived support from the partner for the improvement of the worker's conditions. They suggest that exchange of information can exist regarding the nature of the perceived change in firm performance. The results have shown that the social exchange perspective that views relational contracts in the form of norms or personal relation itself a driver for inter-firm trust, cooperation and information exchange, is an effective means of governance. Cooperation and information exchange behaviour of supplier firm towards their buyer is motivated by rewarding trustworthy reactions (Awan \& Kraslawski, 2017).

Social performance defined as "ethical code of conduct for growth and human survival that should be achieved in an inclusive, connected equitable and prudent manner" (Sharma \& Ruud, 2003). The same may be true and give rise to the relational governance rather than the contractual governance Some scholars also suggest that formal contracts have a direct effect on the economic performance (Arranz \& de Arroyabe, 2012; Liu et al., 2009). Social performance defines as the "incorporate the health and safety issues, improvement of environmental issues and child labours (Hutchins \& Sutherland, 2008). Accordingly Luzzini, Brandon-Jones, Brandon-Jones and Spina (2015) argue that cooperative arrangements with an external partner are beneficial when focusing heavily on improving social sustainability initiatives. Awan, Kraslawski and Huiskonen (2018b) define social sustainability a system of coordinated social interaction practices for the management of the social impact on people and society with the key internal and external stakeholders. This all happens for creating, developing and delivering the best social and ethical code of conduct. The aim is to have value for the survival of current business system (customers, partners and society) and its growth for the future generation equitably and prudently.

The empirical evidence suggests that relational governance is positively associated with the social performance improvements (Awan \& Kraslawski, 2017). Furthermore, the ability to implement process successfully and continuously is crucial, resides mainly with the firm employees, who constitute learning capability, acquire resources and knowledge. Thus, joint problem solving could also result in improved supplier's performance. Finally, collaborative communication enhances supplier's performance by allowing both buyer and supplier to complete tasks more effectively (Cai, Yang \& Hu, 2009). The export manufacturing firms in Pakistan require the compliance to these collaborative ties. This requirement compels the managers to engage themselves with external cooperative behaviours to buyers boost the firm capacity to comply with the requirements and improve internal environmental conditions (Awan, Kraslawski \& Huiskonen, 2018b). Resource-based view emphasizes how the firm may achieve performance outcomes by developing intangible and tangible resources. From a resource-based perspective, firm interaction with different buyers helps firms with the development of new learning capabilities they can leverage to enhance their competitive advantage (Barney \& Felin, 2013). Firm social performance improvement can be explained 
by a set of core different learning capabilities linked to the firm relational governance. Learning from their buyers in exchange of information can help firms to offer new opportunities in the development of process development. For these firms, development of learning capabilities for development of new process as a key internal resource in order to improve social performance.

Thus, we hypothesise that:

Hypothesis 1: Relational governance in export markets is positively associated with social performance improvements.

Innovation is a term that connotes the development of new products, processes and ideas (Burrus, Graham \& Jones, 2018). Joshi, Das \& Mouri (2015) define innovativeness as “an organisation's proclivity to engage in and support new ideas, creativity, novelty, and experimentation that may lead to new products, services, and processes". A firm must acquire required information from every possible source to develop leading-edge innovative products to fulfil the market's needs (Makri, Theodosiou \& Katsikea, 2017; Weerawardena, Mort, Liesch \& Knight, 2007). Improving aspects of innovation performance such as product and process design and manufacturing flexibility mean that more tacit, and organisation-specific information has to be shared between buyers and suppliers, which requires trust (Blomqvist, Hurmelinna \& Seppänen, 2005). More information exchange in a relational relationship, may enhance trust and reduce the concern associated with this information sharing, encouraging buyer and suppliers to act ambitious (Carey, Lawson \& Krause, 2011).

Recent empirical evidence emphasizes the important role of information acquisition about customers and competitors in increasing firm performance through the advancement of innovativeness (Ozkaya, Droge, Hult, Calantone \& Ozkaya, 2015). Organizational culture has a mediating effect on performance (Gorondutse \& Hilman, 2016). Firms engaged in intense information exchange naturally enhance their process of information gathering and analysing, which greatly contributes to their capability to support novelty, creativity and research and development (Makri et al., 2017). Export manufacturers can enhance its innovation performance improvements by increasing focus on relational governance (Awan, 2018). These sustainability practices could create a competitive advantage and are the part of the firm's resources and capabilities which integrated into the Resource Base View (RBV) attempt to build variability performance across the firm (Barney, 1991). We argue that repeated interactions lead to developing mutual understanding, sharing of information and resources, may help to find new ways to develop process and products. Thus,

Hypothesis 2: Relational governance in export markets is positively associated with innovation performance improvement.

\subsection{Mediation Effect of Meta-Cognitive CQ and Cognitive}

The dramatic change in the global business environment and frequent interaction between the stakeholders in the conduct of business is required cultural intelligence skills in the management (Tuan, 2016). According to (Van Dyne, Ang \& Koh, 2008: page 17), metacognitive is an individual ability to acquire and understand other cultural knowledge during interactions with those from the different cultural background. It essentially reflects the ability to form strategies before an intercultural interaction, check about key assumptions and cultural bonding thinking and adjust mental maps, when the experience is different from expectations. When people adopting a metacognitive approach to differences and dispute resolution are likely to focus on arguments that reflect own cultural position as legitimate while adopting the other cultural claim and demands as valid and supported standards that govern the mutual relationships. This cooperative frame entails norms, practices and belief regarding social practices and leads to behaviours aimed at gaining mutually agreed performance outcomes. Thus, a cooperative frame will lead to an interest-based approach for dispute resolution (Lumineau \& Malhotra, 2011).

Cognitive CQ, which refers to an individual's use of its cultural practices, norms and conventions in different cultural settings (Van Dyne et al., 2008), can be used to understand both differences and similarities among cultures. Cognitive CQ directly reflects mental maps about own and other culture mainly knowledge about social, legal and economic systems in a specific context (Earley \& Gardner, 2005). Metacognitive and cognitive are not mutually exclusive. However, that approaches can have consequences for whether and how the differences and dispute are 
resolved. It is possible that both of these two frames will be activated within the same dispute (Fiske \& Taylor, 1991). The presence, under a systemic perspective, of homogeneous cultural values and practices in which collaboration actors can be identified may strengthen the group membership or establish a social network that facilitates interactions among its members (Vilana \& Monroy, 2010).

The use of these approaches is especially likely when the difference and conflict are complex. For example, when there are areas of disagreement as well as agreement on how many women will be employed for a particular task, to have gender equality. Differences may arise due to the locally culturally practices and another partner culture-specific context. In other words, metacognitive and cognitive CQ may be sufficient to be effective in interaction with different cultural backgrounds if the situation is required to adopt another perspective in certain situations even they know what they should do and have the necessary own cultural knowledge. We argue that complexity of intercultural behaviour, metacognitive and cognitive capable individual developmental maps and then adjust the maps that help them to reach accurate expectations to form strategies of interacting with different cultural background individuals.

The effectiveness of learning CQ capability to adapt or acquire behaviours appropriate for culture adjustments. According to the RBV, individuals interact and learn new skills to adapt or acquire behaviours appropriate for culture adjustments (Earley, 2002). Organizational culture is rare as it is different from other organization (Barney, 2001) and it aligned organizational strategic goals and led to cultivating competitive advantage. Thus, the firm requires dynamic capability in a cross-cultural context, "as it is defined as firm's capability to integrate, build, and reconfigure internal and external competencies with response to rapidly changing environments". (Teece \& Pisano, 2004). Thus, these differences in coordination routines provide a great impact on developing rare and intangible assets, help to deploy effectively to gain performance. A firm with this capabilities tends to generate capabilities (Moon, 2010). Crosscultural coordination integration reflects the organisation's capability for effectively and efficiently integrating external and internal resources and competencies. Cultural intelligence is consists of knowledge, thinking, motivation and behaviours and is an adaptive cultural capability (Awan \& Kraslawski, 2017). Here, applying RBV, we argue that:

Hypothesis 3: Meta-cognitive cultural intelligence significantly mediates the relationship between relational governance and social performance improvement.

Hypothesis 4: Cognitive, cultural intelligence significantly mediates the relationship between relational governance and firm social performance.

\subsection{Mediation Effect of Social Performance}

Social interaction ties have also been linked to performance improvements and value creation in buyer-supplier relationships (Cousins, Handfield, Lawson \& Petersen, 2006). Further, Aydin and Ceylan, (2008) argue that, in organisations, people come together and try to connect the interdependent parts of the mechanism for the social system to improve the efficiency of organizational development. Through formal interaction ties and integration of resources, improved operational efficiencies and product design (Cousins et al., 2006). Social sustainability issues in the manufacturing supply chain are growing and there is need to conduct future research on the aspects of the social sustainability and performance (Hoejmose, Brammer \& Millington, 2013; Sarkis, Helms \& Hervani, 2010; Zorzini, Hendry, Huq \& Stevenson, 2015).

Supply chain researchers have pointed out the importance to achieve sustainability performance (Carter \& Rogers, 2008; Klassen \& Vereecke, 2012; Pagell \& Wu, 2009; Sancha, Gimenez \& Sierra, 2016). This creates a sense of satisfaction, which in turn employee can be directed to generate more ideas, focus on reducing cost, and reduce product time (Carey et al., 2011). Business practices related to sustainability are an approach which firms adopted by altering or modifying their current established practices and rules (Engardio, Capell, Carey \& Hall, 2007). Organizations are required to make continuous changing into their internal operations to compete competitively in ever changing the environment in the global place (Schoenherr, 2009). We argue that social performance improvement brings excellent insights into process-based practices, which makes firms more efficient by reducing the accidents at workplace, improving the work conditions and compliance with the procedures. Such activities may stimulate not only process and product innovation but also in the administration process, which can contribute 
towards significant operational efficiency and knowledge integration. Here applying RBV, we suggest that innovation performance improvement is importantly influenced by a firm that continuously improves the process and improves production environment. All of these resources exert a significant positive effect on the innovation performance. We argue that such improvement in process and production environment is critical mechanisms for knowledge combination, which could help the firm to introduce new products. Thus,

Hypothesis 5: Social Performance improvement is positively and significantly mediates the relationship between relational governance and innovation performance improvement.

In summary, we propose a conceptual model as shown in Figure 1.

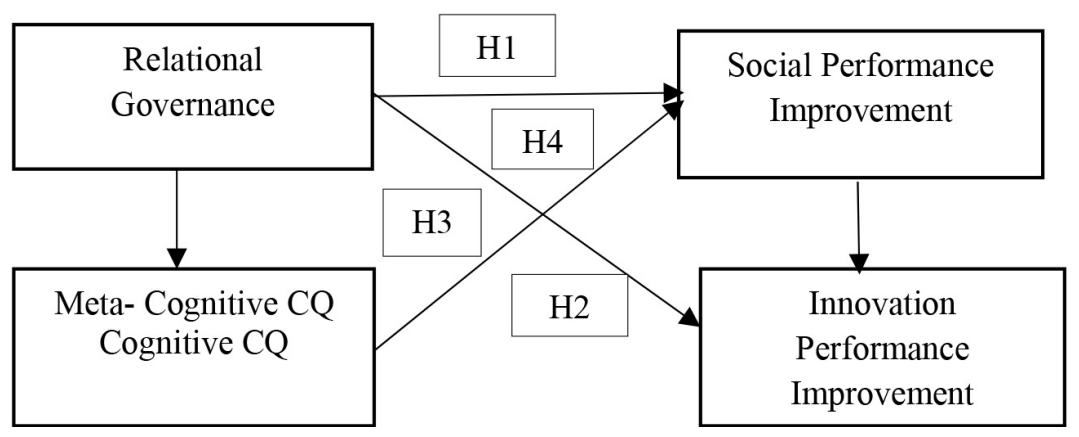

Figure 1. Conceptual Framework

\section{Methodology and Data Collection}

\subsection{Measures and Samples}

The construct of CQ is consist of 20 items assesses each of the four subscales: cognitive, metacognitive. Motivational and behavioural) (Ang, Rockstuhl \& Tan, 2015). Hence, the construct of CQ was adapted (Ang \& Inkpen, 2008; Earley \& Ang, 2003). All items and construct were adapted from previous studies and were measured by using a seven-point Likert scale, which ranged from 1 ("not at all") to 7 ("to a strong extent"). The items of social performance use 7 points Likert scale 1: not at all, 2: a limited extent, 3: slightly improve 4: neutral, 5: a moderate extent, 6: a great extent, 7: a very great extent). We adapted existing measures from previous studies, relational governance (Lusch \& Brown, 1996), and social performance (Awaysheh \& Klassen, 2010; Kleindorfer, Singhal \& Wassenhove, 2005). The reliability and convergent validity of the CQ scale have been established in previous studies (Van Dyne, Ang, Ng, Rockstuhl, Tan \& Koh, 2012). Respondents were asked to consider the extent to which they had improved the social performance while collaboration with their customers from the last three years. Innovation performance scaled was measured using establishes scale, adapted from (Kotabe, Martin \& Domoto, 2003). The adopted scales were measures with seven levels by using a seven-point Likert scale. Scale items are presented in Appendix A.

\subsection{Data Collection}

We test our research model and hypotheses using survey questionnaire data on export manufacturing firms in Pakistan. This study uses Pakistan manufacturer exporters as an empirical setting to test the hypothesis. Currently, Pakistan is also emerging economy and globalization sustainability challenges result in both pressure and drivers for Pakistanies exporter firms to engage with their buyers and understand partner cultural knowledge by engaging with more inter-firm relationship activities in global supply chain networks to improve their social performance. Pakistanies culture has a strong tradition for inter-organizational and inter-personal in supply chain relationships. Pakistan is an emerging economy based on the collaboration with partners and relationship, which is an important factor influencing social performance improvement in many firms. Thus, Pakistan provides a right context to test the interplay among the variables, such as cultural intelligence, social performance improvement and innovation performance improvement. Pakistan is a global production base of textile, sports goods and surgical instruments, exporting a wide variety of goods to Europe and Western countries. Pakistan recent rise importer and exporter inter-frim problems have emerged due to weak regulations and institutional system that have caused international 
concerns related to its transaction arrangements not only on the social issues but also on health issues in surroundings of the firm facility.

The questionnaire reviewed by supply chain management academic experts and then pretested among 12 manufacturing firms (excluded in the final analysis) to gain clarity of content and improve readability. We made minor modifications in two items; two items were deleted due to low factor loadings each from contractual governance and social performance. We randomly drew a sample of Pakistan manufacturer exporters from the database of Federal Chamber of Commerce Industry of two major cities. A random sampling technique was used for choosing the appropriate firms and identified 650 firms matching our sampling criteria. After having eliminated those firm did not meet the at least five years exporting experience as well as those who did not have complete contact details.

A sample of 650 manufacturing firms contacted by telephone for their participation and request the designation of key informants, 316 firms responded to participate in the survey. The key respondents in this study were senior supply chain managers. All key respondent firms were told that survey mainly contained questions related to their governance of supply chain relationships. Out of 316 firms, 257 firms completed the questionnaire. In total, we obtained 186 questionnaires in the first three weeks. We then followed by telephone calls and through sending them an email, and 71 responses were received after the three weeks. As a result of this approach, 257 responses were received, of which 18 response were unusable due to missing values, and firm respondents lack knowledge, resulting in 239 useable responses. The key informants came from executive's level positions managed and involved in decision makings, such as Managing director, General manager, Director supply chain and logistics and Director import and exports.

Our sample covered a wide range of industries, including textile, sports, surgical. We make appointments with the key informants and solicit their cooperation to participate in the survey. The key informants assured that all provided information would be used only for the academic purpose. To assess the non-response bias, we divide the sample into early and late respondents (Armstrong \& Overton, 1977). This study used independent sample t-test to compare early and late respondents. The result of Leven's test of equality of variance of each variable were $\mathrm{p}>0.05$. The results reveal that those of who responded early and later to this study's survey did not provide a significant difference. This supports the notion that non-response bias is not a concern for this study.

\subsection{Measurement Assessment}

The hypotheses were tested in structural equation model (SEM) with maximum likelihood estimation in Analysis of Moment Structures (AMOS) with Statistical Package for Social Science for Windows 23 version used to analyses the hypothesised model (Arbuckle, 2014). Collected data were analysed with statistical package for social science (SPSS) and AMOS v.23, an appropriate method particularly suitable when values of a parameter that has more than one solution (Byrne, 2016). We calculated the descriptive statistics, and missing data were found to be missing at random, we replaced missing value with multiple imputation methods (Hair, Black, Babin \& Anderson, 2010). Skewness and multivariate kurtosis of the scales was assessed using Mahalanobis distance test. The results reveal that skewness and kurtosis fall within the recommended range. Mahalanobis distance value greater 57.437 at $\mathrm{p}<0.01$ was considered for potential outliers. Skewness, kurtosis and normality of data were assessed using the guidelines of (Hair et al., 2010). The Kolmogorov-Smirnov test used to assess the normality of data; the results provide evidence that we met the assumptions of normality $\mathrm{p}>0.05$, as suggested by (Hair et al., 2010).

\subsection{Data Analysis}

To assess a better subset of the measurement construct, exploratory factor analysis (EFA) was conducted with a varimax solution on all the items. The obtained component matrix provides an adequate fit. The Kaiser-Meyer-Olkin (MSA) estimate for the data set was 0.822. The items measures were largely grounded in the western literature, while data were collected in Pakistan. In Table 1, we reported means, standard deviations and person correlations for all the variables. 


\begin{tabular}{|l|c|c|c|c|c|c|c|c|c|}
\hline & RG & SP & IP & MEQ & COG & PE & WE & FS & FA \\
\hline RG & 0.805 & & & & & & & & \\
\hline SP & $.295^{* *}$ & 0.805 & & & & & & & \\
\hline IP & $.195^{* *}$ & $.208^{* *}$ & 0.882 & & & & & & \\
\hline MEQ & $.176^{* *}$ & $.303^{* *}$ & .069 & 0.796 & & & & & \\
\hline COG & $.11 *$ & $.16^{* *}$ & $.106^{*}$ & $.118^{* *}$ & 0.810 & & & & \\
\hline PE & .058 & -.099 & .037 & -.017 & .046 & 1 & & & \\
\hline WE & -.049 & -.022 & -.076 & .018 & -.068 & -.085 & 1 & & \\
\hline FS & -.006 & -.018 & $-.117 *$ & -.084 & -.020 & $.119 * *$ & $.537 * *$ & 1 & $.524 * *$ \\
\hline FA & -.007 & -.031 & -.060 & -.015 & -.003 & .029 & $.540 * *$ & .52 & 0.81 \\
\hline M & 6.02 & 6.11 & 5.69 & 5.73 & 5.99 & 0.38 & 0.73 & 0.82 & 0.43 \\
\hline SD & 0.59 & 0.60 & 0.92 & 0.87 & 0.63 & 0.489 & 0.35 & 0.33 & 0.47 \\
\hline
\end{tabular}

Notes: Results from EFA. Diagonally bold values are the square root of average variance extracted. COG = Cognitive; FA: Firm Age; FS: Firm Size; IP: Innovation Performance; M: Mean; MEQ: Meta Cognitive; PE: Level of Education; RG: Relational Governance; SD: Standard Deviation; WE: Work Experience. ${ }^{* *}$ Correlation is significant at the $\mathrm{p}<0.01$ level.

Table 1. Mean, Standard deviation and results of discriminant validity

The correlation of all the items ranged from 0.18 to 0.69 significant at 0.1 and 0.05 percent significance level (Hair et al., 2010). Confirmatory factor analysis (CFA) was performed using AMOS23. (AMOS: Analysis of Moment Structures) (Arbuckle, 2014). CFA is a desirable analytical technique for conducting validation studies (Byrne, 2016). The value of $\chi^{2}$ is sensitive to sample size. We calculated the ratio of chi-square to the degree of freed (df), Tabachnick and Fidell (2007), the value of $\chi^{2} \mid \mathrm{df}<3$ at $\mathrm{p}<0.05$ as acceptable model fit (Kline, 2015).

In addition to confirm the factor structure found in EFA, comparative fit indices (CFI > 0.90; Bentler and Bonett 1980), Goodness of fit indices (GFI > 0.95); Adjusted Goodness of fit indices (AGFI > 0.90); the Tucker-Lewis index (TLI > 0.95); the root mean square residual (SRMR < 0.08; Jöreskog \& Yang, 1996) and the Root Mean Square Error of Approximation (RMSEA < 0.06; Hu, Bentler \& Hoyle, 1995).

\subsection{Reliability and Validity Measure}

We tested measurement and structural model using covariance-based structural equation modelling (CB-SEM) with AMOS 23 with maximum likelihood estimation except for mediation analysis. The mediation analysis was performed using the guidelines (Baron \& Kenny, 1986) and tested model with (Preacher \& Hayes, 2008) Process macro with SPSS. Only those measurement items with factor loadings larger than 0.60 and with statistical significance less at 0.01 and 0.05 retained for further analysis. The results of exploratory factor analysis also demonstrated that all the constructs are discriminate, no items were cross loaded, established the discriminant validity (Anderson \& Gerbing, 1988). Further to reinforce the construct validity of the measurement model, a chi-square difference test compared with the constrained and unconstrained model (Netemeyer, Johnston \& Burton, 1990). The resulted factors scores were above 0.50 for all the variables and explained $63.21 \%$ total variance extraction. The results of factors loadings are presented in Table 2 .

The results provide the necessary evidence that all the constructs exhibited convergent validity. Average variance extracted (AVE) capture a quantity of variance through its items through the construct and amount of measurement error should greater than 0.50. Composite reliability (CR) coefficients for each construct also exceeded the recommended 0.60 benchmarks (Bagozzi \& Yi, 1988), and the average variance extracted (AVE) for all scales exceeded the recommended threshold, AVEs for all construct were greater than the 0.50 cut of value (Anderson \& Gerbing, 1988). (Fornell \& Larcker, 1981). The AVE is also applied to determine the discriminant validity. The correlation matrix of all construct and square root of AVE. The AVE of all construct is greater than 0.5, which shows that correlation of all the items is less than the square root of average variance extracted, further establish the discriminant validity of the scales. The results indicate AVE and Cronbach's alpha and CR exceed the cutoff values 
of 0.70 (Fornell \& Larcker, 1981; Hair et al., 2010). The discriminant validity of the measures evaluated by comparing the AVE for each measure with the respective squared correlation between the two constructs (Fornell \& Larcker, 1981).

\begin{tabular}{|c|c|c|c|}
\hline Items & $\begin{array}{c}\text { Factor } \\
\text { loadings }^{\mathrm{a}}\end{array}$ & $\begin{array}{c}\text { Error } \\
\text { variance }\end{array}$ & $\begin{array}{l}\text { Construct } \\
\text { reliability }\end{array}$ \\
\hline \multicolumn{4}{|c|}{ Relational Governance } \\
\hline RG1 & 0.864 & 0.254 & 0.746 \\
\hline RG2 & 0.805 & 0.352 & 0.648 \\
\hline RG3 & 0.772 & 0.404 & 0.596 \\
\hline RG4 & 0.778 & 0.395 & 0.605 \\
\hline \multicolumn{4}{|l|}{ Social Performance } \\
\hline SP1 & 0.770 & 0.407 & 0.593 \\
\hline SP2 & 0.850 & 0.278 & 0.722 \\
\hline SP3 & 0.827 & 0.316 & 0.684 \\
\hline SP4 & 0.774 & 0.401 & 0.599 \\
\hline \multicolumn{4}{|c|}{ Innovation Performance } \\
\hline IP1 & 0.857 & 0.266 & 0.734 \\
\hline IP2 & 0.887 & 0.213 & 0.787 \\
\hline IP3 & 0.902 & 0.186 & 0.814 \\
\hline IP4 & $0.495^{*}$ & - & - \\
\hline \multicolumn{4}{|l|}{ Meta-cognitive CQ } \\
\hline MEQ1 & 0.817 & 0.333 & 0.667 \\
\hline MEQ2 & 0.821 & 0.326 & 0.674 \\
\hline MEQ3 & 0.749 & 0.439 & 0.561 \\
\hline \multicolumn{4}{|l|}{ Cognitive CQ } \\
\hline COQ1 & 0.730 & 0.467 & 0.533 \\
\hline COQ2 & 0.871 & 0.241 & 0.759 \\
\hline COQ3 & 0.823 & 0.323 & 0.677 \\
\hline
\end{tabular}

*Items deleted in EFA due to low factor loadings and insignificant results.

Table 2. Validation of constructs Survey items, item means, standard deviation

In this study, the composite reliability for all variables ranged between 0.70 (see Table 3). The measurement model allows us to decide whether the unidimensionality is in modelling is warranted (Hu et al., 1995; Kline, 2015). The results of CFA show that model consists of the data and factor loadings are statistically significant at $\mathrm{p}=0.05$. Thus all item related strongly to its intended latent construct. Validity and reliability assessed using CFA and it involves all items loaded on its related construct. Every pair of constructs passed the test. Overall, the results showed acceptable reliability and validity for all the variables. The structural model had an acceptable model fit. $\chi^{2}=335.04$ $(\mathrm{df}=236)$, root mean square error of approximation RMSEA $=.053$, goodness-of-fit index $(\mathrm{GFI})=0.952$, $\mathrm{IFI}=.947$; comparative fit index CFI $=.943$. 


\begin{tabular}{|l|c|c|c|}
\hline \multicolumn{1}{|c|}{ Items } & $\begin{array}{c}\text { Average variance } \\
\text { extraction }\end{array}$ & $\begin{array}{c}\text { Composite } \\
\text { reliability }\end{array}$ & $\begin{array}{c}\text { Cronbach's } \\
\text { alpha }\end{array}$ \\
\hline Relational Governance & 0.649 & 0.820 & 0.80 \\
\hline Social Performance & 0.649 & 0.881 & 0.819 \\
\hline Innovation Performance Improvement & 0.778 & 0.913 & 0.760 \\
\hline Meta cognitive & 0.634 & 0.838 & 0.720 \\
\hline Cognitive & 0.656 & 0.851 & 0.744 \\
\hline
\end{tabular}

Table 3. Validity and Reliability of constructs Survey items

Hypothesis 1 predicts a positive relationship between relational governance and social performance improvements. Result analysis indicated that relational governance is significantly associated with firm improvement in social performance $(\beta=0.24, \mathrm{t}=4.96, \mathrm{p}<0.05)$ by controlling Control firm age and firm size, providing support for the H1. The findings are consistent with the findings of (Awan, 2018; Awan \& Kraslawski, 2017). The findings indicate that relational governance enhances trust that enables individuals to come up with new ideas during interactions; this is likely to be the key driver to transform ideas into practicability to improve the social quality of life for their workers and society. This might indicate that when an export manufacturer implements relational governance, it reinforces the possibility of being involved with the importer, exchange of information and joint planning significant impact on social performance improvement. Whereas relational governance is also positive and significantly associated with the innovation performance improvement. $(\beta=0.16, \mathrm{t}=3.434, \mathrm{p}<0.05)$, providing support for H2. The results show that social performance improvement has a positive effect on innovation performance improvement $(\beta=0.19, \mathrm{t}=2.731, \mathrm{p}<0.05)$. The findings are consistent with the findings of (Awan, 2018). That is, to transform the impact of its employee well-being on innovation performance improvements, exporter firms must suitably improve process and production facilities. In sum, the results certainly show that export firms with better health and safety policies, better working conditions, compliance with human rights can achieve a product or process innovation.

The mediation analysis of cultural Intelligence (CQ) between the governance mechanism and social performance to the firm were tested using preacher and (Preacher \& Hayes, 2008) macro process for SPPS. We test indirect and total effects to account for potential mediation through cultural intelligence. We followed the causal step approach in testing for mediation proposed by (Baron \& Kenny, 1986) and a bootstrap approach (Bollen, Lennox \& Dahly, 2009). We examined mediation analysis via the PROCESS macro developed by (Preacher \& Hayes, 2008) in SPPS, using $95 \%$ confidence interval (CI) with 5000 re-sample bootstrapping. We also report $\mathrm{K}^{2}$ statistics to provide a standardised effect size for any significant effects following recommendation for estimating "the proportion of the maximum possible indirect effect that could have occurred" (Preacher \& Kelley, 2011).

According to the results, meta-cognitive (MCQ) and cognitive (COQ) positively associated with the social performance improvements (see Table 1). The first condition for mediation effect of MCQ, COQ is fulfilled. The total effect of relational governance, and social performance improvement is significant and positive $(\beta=0.39$, $\mathrm{t}=6.62, \mathrm{p}<0.05)$. In Hypothesis 3 , it was proposed the MCQ positively, and significant mediates the relationship between the relational governance and social performance improvements. Subsequently, indirect effect of relational governance and social performance improvement is significant and positive $(\beta=0.042, \mathrm{t}=2.731, \mathrm{p}<0.05)$. Thus, there are chances for either partially or fully mediation relationship. To test whether there is full or partial mediation; the direct effect is examined. The path coefficient for a direct effect of relational governance on social performance improvement after introducing of mediating variable is found positive and significant $(\beta=0.35, \mathrm{t}=6.0, \mathrm{p}<0.05)$. Thus partial mediation is concluded.

Prior research has also proposed that cultural intelligence measures taken together could be used at a firm level in the context of international business context (Ang \& Inkpen, 2008). Managers with a high level of Metacognitive CQ skills likely to adjust their counterpart cultural knowledge. The high level of metacognitive CQ suggested that supplier firm's individual has acquired and brought to the firm partner cultural knowledge in facilitating the development of the critical resource. In Hypothesis 4, it was proposed that cognitive, cultural intelligence (COQ) 
mediate the relationship between the relational governance and social performance improvements. In contrast the indirect effects of cognitive (COQ) is not statistical significant, $(\beta=0.0096, t=1.031, p>0.05)$, Rejected H5. The results of mediation analysis shown in Tables 4 and 5 respectively for MCQ and COQ. Our results reveal that exporting firms need to adapt, reconfigure cultural knowledge and integrate resources into the operations so that they can proactively improve social performance and achieve superior innovation performance. We suggest that cultural intelligence capabilities with relational governance in exporting manufacturing firms in emerging market can promote social cohesion between partners. Social cohesion can be used to attempt to establish a link to a lost moment of social harmony (Pahl, 1991). Social cohesion is emerging through cultural intelligence, which serves to bring suppliers and buyers together to work jointly and improve collaboration. The idea of cultural intelligence capability (CQ) lens is to ensure supply chain operations proceed in harmony with partner cultural context (Awan, Kraslawski \& Huiskonen, 2018a).

\begin{tabular}{|c|c|c|c|c|c|c|c|c|}
\hline \multirow{2}{*}{ Relationship } & \multicolumn{3}{|c|}{ Total effect (c): } & \multicolumn{3}{|c|}{ Direct effect $\left(c^{\prime}\right)$ : } & \multicolumn{2}{|c|}{ Indirect effect } \\
\hline & b & $\mathrm{t}$ & SE & b & $\mathrm{t}$ & $\mathrm{SE}$ & b & SE \\
\hline $\mathrm{RG}$ to $\mathrm{SP}$ & .397 & 6.62 & .061 & .35 & 6.00 & .05 & .042 & .025 \\
\hline LLCI & .2794 & & & & .2386 & & .0094 & \\
\hline ULCI & .5162 & & & & .4714 & & .1156 & \\
\hline Sobel test results & & & $\mathrm{b}=0$ & $\mathrm{E}=$ & $=2.24$ & 0.024 & & \\
\hline
\end{tabular}

Standardized results based on 5000 bootstrap samples in Hayes's (2013) PROCESS macro. Bias-corrected 95\% confidence interval reported in brackets.

Table 4. Direct, and indirect effects of RG on Social performance through Meta-cognitive CQ

\begin{tabular}{|l|c|c|c|c|c|c|c|c|}
\hline \multirow{2}{*}{ Relationship } & \multicolumn{3}{|c|}{ Total effect $(c):$} & \multicolumn{3}{c|}{ Direct effect $\left(c^{\prime}\right):$} & \multicolumn{2}{c|}{ Indirect effect } \\
\cline { 2 - 9 } & $\mathrm{b}$ & $\mathrm{t}$ & $\mathrm{SE}$ & $\mathrm{b}$ & $\mathrm{t}$ & $\mathrm{SE}$ & $\mathrm{b}$ & $\mathrm{SE}$ \\
\hline SP to IP & .397 & 6.62 & .061 & .382 & 6.50 & .05 & .0096 & .0126 \\
\hline LLCI & .2794 & & & .2707 & & & -.0043 & .0515 \\
\hline ULCI & .5162 & & \multicolumn{7}{|c|}{5058} & & & & \\
\hline Sobel test results & \multicolumn{7}{|c|}{$\mathrm{b}=0.008, \mathrm{SE}=.010, \mathrm{Z}=0.92, \mathrm{p}=0.367$} \\
\hline
\end{tabular}

Standardized results based on 5000 bootstrap samples in Hayes's (2013) PROCESS macro. Bias-corrected 95\% confidence interval reported in brackets.

Table 5. Direct, and indirect effects of RG on Social performance through Cognitive CQ

In Hypothesis 6, it was predicted social performance improvement significant mediation relationship between the relational governance and innovation performance improvements. The total effect of relational governance, and social performance improvement is significant and positive $(\beta=0.39, \mathrm{t}=6.62, \mathrm{p}<0.05)$. Subsequently, indirect effect of relational governance and innovation performance improvement is significant and positive $(\beta=0.09$, $\mathrm{p}<0.05)$. Thus, there are chances for either partially or fully mediation relationship. To test whether there is full or partial mediation; the direct effect is examined. The path coefficient for a direct effect of relational governance on innovation performance improvement after introducing of mediating variable is found insignificant $(\beta=0.20$, $p>0.05)$. The findings are consistent with the findings of (Pavelin \& Porter, 2008). The innovation performance improvement tends to be positively associated with export firms those who have improved social performance. The mediation analysis of social performance between relational governance and innovation performance improvement shown in Table 6. Findings from this research highlight other factors, which leverage social performance to deliver enhanced innovation performance outcomes, beyond relational governance. These findings imply that firms with a superior supporting work environment (social support, physical factors, and internal satisfaction) positively associated with the ability to design new process and development of products. 


\begin{tabular}{|l|c|c|c|c|c|c|c|c|}
\hline \multirow{2}{*}{ Relationship } & \multicolumn{3}{|c|}{ Total effect $(c):$} & \multicolumn{3}{c|}{ Direct effect $\left(c^{\prime}\right):$} & \multicolumn{2}{c|}{ Indirect effect } \\
\cline { 2 - 9 } & $\mathrm{b}$ & $\mathrm{t}$ & $\mathrm{SE}$ & $\mathrm{b}$ & $\mathrm{t}$ & $\mathrm{SE}$ & $\mathrm{b}$ & $\mathrm{SE}$ \\
\hline CG to IP & .303 & 3.06 & .106 & .20 & 1.94 & .05 & .095 & .043 \\
\hline LLCI & .1085 & & & & -.0019 & & .0211 & .1990 \\
\hline ULCI & .4977 & & & & .4181 & & & \\
\hline Sobel test results & \multicolumn{7}{|c|}{$\mathrm{B}=0.095, \mathrm{SE}=.044, \mathrm{Z}=2.113, \mathrm{p}=0.034$} \\
\hline
\end{tabular}

Standardized results based on 5000 bootstrap samples in Hayes's (2013) PROCESS macro. Bias-corrected 95\% confidence interval reported in brackets.

Table 6. Direct, and indirect effects of RG on Innovation performance through Social Performance

\section{Discussions}

The present research provides new insight into the literature in following ways. First, recent research has begun to emphasise the importance of sustainability on innovation (Macchion et al., 2017), no empirical research has examined the nature of the relationship between social performance and innovation performance outcomes in exporting context. Drawing on the resource-based view (RBV) and empirically tests a conceptual model investigating a set of relational governance, cultural intelligence, and social performance effect on innovation performance improvement. Our results reveal the importance of meta-cognitive CQ effect on social performance improvements. These results consistent of the findings of past studies on relational governance and cultural intelligence. Strategic orientation towards cultural intelligence should be integrated into the company's governance mechanism (Awan et al., 2018a). The export firms in Pakistan require the adaptation to the cultural norms and values of partner culture in cross-border supply chain relationships. This requirement compels firms to engage themselves with crosscultural training, is key to successful collaboration.

Our results reveal that exporting firms in Pakistan likely to adapt to the partner cultural preferences, resolve differences, resulting in the more significant exchange of information and increase collaboration has an impact on the social performance improvement. Chua, Morris and Mor (2012) reported positive effects of meta-cognitive CQ on collaboration. The results showed that repeated interaction and exchange of information might allow the firm to articulate one's knowledge and improve the understanding of the partner culture. This could because of that, Pakistan cultural norms favour cooperative norms, which smoothly articulate and questioning ones the mental model is important for effective learning. It allows an individual to transcend existing knowledge and engage in double-loop learning (Sun \& Anderson, 2010). Second, our findings highlight the urgency of adopting a more integrated approach to study the effect of social performance on innovation performance. We especially contended with a growing stream of research, supporting that performance benefits of innovation do not merely result from relational governance. We extend the literature on innovation by showing that, relational governance enable the organisation to increase collaboration, enables the improvement of social performance, which in turn results in the firm's increase success in innovation.

\section{Conclusions}

This study contributes to a growing field of research in manufacturing and supply chain relationship by demonstrating how relational governance shapes the relationship between social performance improvement and innovation performance improvement. In this paper, we investigate how relational governance influences on firm's cultural intelligence capability and social performance improvements. By applying, resource-based view, we provide evidence that relational governance effects firm cultural intelligence development from adoptability to adaptability for social performance improvements. The conceptual model we develop reinforce this implication that there is a positive mediation effect of cultural intelligence between relational governance and social performance improvements. We provide conceptual evidence to demonstrate that cultural understanding and adaptability in a buyer-supplier relationship can develop learning capabilities for social sustainability. Our results highlight the importance of cultural intelligence a guiding principle for the development of buyer-supplier relationships and deployment of learning resources. The export manufacturer that are likely to see social performance improvement 
in the coming decades that are not only doing business internationally through relational governance but that are developing the strategic cultural intelligence capability to successfully doing business internationally.

The results show a positive association between firm-level meta-cognitive cultural intelligence capabilities and social performance improvement. Similarly, results show an indirect association social performance improvement between relational governance and innovation performance improvement. Improvements. Our results suggest that innovation performance improvements positively depend on the capacity of the firm to activate participate in relational governance but also on social performance improvements. These findings imply that firms with a superior supporting work environment (social support, physical factors, and internal satisfaction) positively associated with the design of new process and development of products. We conclude that firm internal capability effects on the buyer-supplier relationship and firm performance improvements. These findings underline the importance of fit between the export-manufacturing firm's cultural intelligence and the resources need to be associated with relational governance. The cultural capability is at the centre of today's sustainable development advantage in the buyersupplier relationship.

Our study contributes to the sustainability literature on supply chain relationship. First, focusing on the role of social performance improvement by export firms in innovation performance. This study shows that innovation performance depends on a firm's continuously sustainability learning practice. Our study moves beyond the direct link between relational governance and innovation performance by identifying social performance improvements a contextual variable in the relationship between relational governance and innovation performance. Second, this study makes theoretical contributions. Our study uses resource-based view (RBV), applying it to the cultural intelligence. The finding that cultural intelligence is influencing the development of other unique knowledge capabilities. Through the use of cultural intelligence, firm increase its ability to sense cultural differences, seize and adapt globally scattered cultural practices on social issues and allows for the development of unique knowledge resources and capabilities, impact on firm social performance and innovation performance improvements.

\subsection{Managerial Implications}

This study offers implications for the practitioners and policymakers. Managers should pay close attention to the cultural differences of the evolving needs of their foreign customers on social issues. This cultural understanding can strongly affect their collaboration development and inter-firm exchange relationship. The unprecedented pace of globalisation and sustainable development, the firm capability to capture and understand social cohesion constitute one important element in the process of development more collaborative ties. Supplier's managers need to understand the extent of the buyer's level of cultural practices on social sustainability issues to implement best sustainability practices. Cross-cultural training of the manager dealing with cross-border partners could simply improve the international collaboration in international business.

Moreover, our study findings indicate that cultural intelligence dimensions affect performance improvements. In this respect, top management in exporting firms should delegate decision making to managers and power sharing. Remarkably, it is found that higher level of cognitive CQ is associated with the coordination and it is crucial for the manufacturers' exporters to learn quickly and to make sense of cultural knowledge in foreign markets. Importantly managers are advised to establish more informal information exchange channels within their company to accelerate the performance outcomes. For managers from developed countries, when purchasing from developing countries suppliers, must consider the higher management have considerable experience and qualified international managers in dealing with the different cultural customers to seek social performance. Our study results suggest that cultural intelligence exists in export manufacturing firms, where suppliers feel part of the buyers, and personal relationship are strong; differences among buyers are respected; and where the partners support supplier managers. The result from this study emphasized cultural intelligence to be treated, as part of social cohesion that deeply rooted in cultural intelligence capabilities of an organisation, is the key to success towards social performance. Furthermore, the supply chain relationship is likely to benefit from cultural intelligence capability when there are differences and disputes on the implementation of different social sustainability practices among buyers and suppliers. 


\subsection{Limitations and Future Research}

This study has the limitation that needs to be addressed. The major limitation is that it is a cross-sectional study with few industries and does not present the whole population. Further research could examine how firms implement governance mechanism by paying particular to draw a comparison between their govern mechanism practices and so social performer in other developing countries (China and India). We restrict our analysis only to Pakistan export manufacturers. Further, it would also be useful to improve our understanding of the relationship between internal governance and institutional differences in implementation sustainable practices. Examination of the mediating role of knowledge acquisition, knowledge sharing and moderating role of sustainable investment on firm performance improvement is an important research area for future researchers. Future research studies could include examining whether the manufacturer re-orientation on ecological is influenced by the customers when they have a contractual relationship with each other. It would be interesting to investigate whether relational governance could lead to developing trust and commitment towards social sustainability issues differ from those of firms in another industrial sector in emerging economies. In light of the growing debate on the role of governance mechanism, future studies should attempt to address to what extent contractual, relational governance mechanisms are a complementary or good substitute for the development of a goodwill trust and commitment to sustainability, and what are the efficiency consequences and antecedents of social performance? However, regarding our conceptual model does not include all dimensions of social performance, there is need to identify the what are the good self-governance mechanism in the different industry upon which social performance measures can be binding in contracts to achieve desired targets. Future research may seek to investigate how and what type of social cohesion is needed in order to improve the buyer-supplier relationships in a sustainable way?

\section{Declaration of Conflicting Interests}

The author(s) declared no potential conflicts of interest with respect to the research, authorship, and/or publication of this article.

\section{Funding}

The author(s) received no financial support for the research, authorship, and/or publication of this article.

\section{References}

Adu-Gyamfi, N., \& Korneliussen, T. (2013). Antecedents of export performance: the case of an emerging market. International Journal of Emerging Markets, 8(4), 354-372. https://doi.org/10.1108/IJoEM-Jun-2011-0056

Anderson, J.C., \& Gerbing, D.W. (1988). Structural equation modeling in practice: A review and recommended twostep approach. Psychological Bulletin, 103(3), 411-423. https://doi.org/10.1037/0033-2909.103.3.411

Ang, S., \& Inkpen, A.C. (2008). Cultural intelligence and offshore outsourcing success: A framework of firm-level intercultural capability. Decision Sciences, 39(3), 337-358. https://doi.org/10.1111/j.1540-5915.2008.00195.x

Ang, S., Rockstuhl, T., \& Tan, M.L. (2015). Cultural intelligence and competencies. International Encyclopedia of Social and Behavioral Sciences, 2, 433-439. https://doi.org/10.1016/B978-0-08-097086-8.25050-2

Arbuckle, J.L. (2014). Amos (version 23.0) [computer program]. Chicago: IBM SPSS.

Armstrong, J. S., \& Overton, T. S. (1977). Estimating nonresponse bias in mail surveys. Journal of Marketing Research, 14(3), 396-402. https://doi.org/10.2307/3150783

Arranz, N., \& de Arroyabe, J.C.F. (2012). Effect of Formal Contracts, Relational Norms and Trust on Performance of Joint Research and Development Projects. British Journal of Management, 23(4), 575-588.

https://doi.org/10.1111/j.1467-8551.2011.00791.x

Awan, U. (2018). Effects of buyer-supplier relationship on social performance improvement and innovation performance improvement. International Journal of Applied Management Science. Forthcommi.

https://doi.org/10.5861/ijrsm.2017.1875 
Awan, U., \& Kraslawski, A. (2017). Investigating the mediating role of cultural intelligence on the relationship between relational governance and firm social performance. International Journal of Research Studies in Management, 6(2), 23-38.

Awan, U., Kraslawski, A., \& Huiskonen, J. (2018a). A Collaborative Framework for Governance Mechanism and Sustainability Performance in Supply Chain. In Freitag, J., Kotzab, M., \& Pannek, H. (Ed.), Dynamics in Logistics: Proceedings of the 6th International Conference LDIC 2018 (Lecture Notes in Logistics, p. 67-75,). Bremen Germany: Springer International Publishing AG. https://doi.org/doi.org/10.1007/978-3-319-74225-0

Awan, U., Kraslawski, A., \& Huiskonen, J. (2018b). Buyer-supplier relationship on social sustainability: Moderation analysis of cultural intelligence. Cogent Business \& Management, 5(1), 1429346.

https://doi.org/10.1080/23311975.2018.1429346

Awan, U., Muneer, G., \& Abbas, W. (2013). Organizational collaborative culture as a source of managing innovation. World Applied Sciences Journal, 24(5), 582-587. https://doi.org/10.5829/idosi.wasj.2013.24.05.1085

Awaysheh, A., \& Klassen, R.D. (2010). The impact of supply chain structure on the use of supplier socially responsible practices. International Journal of Operations \& Production Management, 30(12), 1246-1268. https://doi.org/10.1108/01443571011094253

Aydin, B., \& Ceylan, A. (2008). The employee satisfaction in metalworking manufacturing: How do organizational culture and organizational learning capacity jointly affect it? Journal of Industrial Engineering and Management, 1(2), 143-168. https://doi.org/10.3926/jiem.2008.v1n2.p143-168

Bagozzi, R.P., \& Yi, Y. (1988). On the evaluation of structural equation models. Journal of the Academy of Marketing Science, 16(1), 74-94. https://doi.org/10.1007/BF02723327

Barney, J. (1991). Firm Resources and Sustained Competitive Advantage. Journal of Management, 17(1), 99-120. https://doi.org/10.1177/014920639101700108

Barney, J.B. (2001). Resource-based theories of competitive advantage: A ten- year retrospective on the resource-based view. Journal of Management, 27, 643-650. https://doi.org/10.1177/014920630102700602

Barney, J., \& Felin, T. (2013). What are microfoundations? The Academy of Management Perspectives, 27(2), $138-155$. https://doi.org/10.5465/amp.2012.0107

Baron, R.M., \& Kenny, D.A. (1986). The moderator--mediator variable distinction in social psychological research: Conceptual, strategic, and statistical considerations. Journal of Personality and Social Psychology, 51(6), 1173-1182. https://doi.org/10.1037/0022-3514.51.6.1173

Bentler, P.M., \& Bonett, D.G. (1980). Significance tests and goodness of fit in the analysis of covariance structures. Psychological Bulletin, 88(3), 588. https://doi.org/10.1037/0033-2909.88.3.588

Blomqvist, K., Hurmelinna, P., \& Seppänen, R. (2005). Playing the collaboration game right-balancing trust and contracting. Technovation, 25(5), 497-504. https://doi.org/10.1016/j.technovation.2004.09.001

Bollen, K.A., Lennox, R.D., \& Dahly, D.L. (2009). Practical application of the vanishing tetrad test for causal indicator measurement models: An example from health-related quality of life. Statistics in Medicine, 28(10), 1524-1536. https://doi.org/10.1002/sim.3560

Brandenburg, M., Govindan, K., Sarkis, J., \& Seuring, S. (2014). Quantitative models for sustainable supply chain management: Developments and directions. European Journal of Operational Research, 233(2), 299-312. https://doi.org/10.1016/j.ejor.2013.09.032

Bstieler, L., \& Hemmert, M. (2015). The effectiveness of relational and contractual governance in new product development collaborations: Evidence from Korea. Technovation, 45(46), 29-39.

https://doi.org/10.1016/j.technovation.2015.07.003

Burrus, R.T. Graham, J.E., \& Jones, A.T. (2018). Regional innovation and firm performance. Journal of Business Research, (June 2017), 1-6. https://doi.org/10.1016/j.jbusres.2017.12.042

Byrne, B.M. (2016). Structural equation modeling with AMOS: Basic concepts, applications, and programming. Oxford, UK: Taylor \& Francis Group Ltd, Routledge. 
Cai, S., Yang, Z., \& Hu, Z. (2009). Exploring the governance mechanisms of quasi-integration in buyer-supplier relationships. Journal of Business Research, 62(6), 660-666. https://doi.org/10.1016/j.jbustes.2008.02.004

Caniëls, M.C. J., Gehrsitz, M.H., \& Semeijn, J. (2013). Participation of suppliers in greening supply chains: An empirical analysis of German automotive suppliers. Journal of Purchasing and Supply Management, 19(3), 134-143. https://doi.org/10.1016/j.pursup.2013.02.005

Cao, Z., \& Lumineau, F. (2015). Revisiting the interplay between contractual and relational governance: A qualitative and meta-analytic investigation. Journal of Operations Management, 33(1), 15-42. https://doi.org/10.1016/j.jom.2014.09.009

Carey, S., Lawson, B., \& Krause, D.R. (2011). Social capital configuration, legal bonds and performance in buyer-supplier relationships. Journal of Operations Management, 29(4), 277-288. https://doi.org/10.1016/j.jom.2010.08.003

Carter, C.R., \& Rogers, D.S. (2008). A framework of sustainable supply chain management: moving toward new theory. International Journal of Physical Distribution \& Logistics Management, 38(5), 360-387. https://doi.org/10.1108/09600030810882816

Charoensukmongkol, P. (2016). Cultural intelligence and export performance of small and medium enterprises in Thailand: Mediating roles of organizational capabilities. International Small Business Journal, 34(1), 105-122. https://doi.org/10.1177/0266242614539364

Chiou, T.-Y., Chan, H.K., Lettice, F., \& Chung, S.H. (2011). The influence of greening the suppliers and green innovation on environmental performance and competitive advantage in Taiwan. Transportation Research Part E: Logistics and Transportation Review, 47(6), 822-836. https://doi.org/10.1016/j.tre.2011.05.016

Christiansen, B. (2015). Nationalism, Cultural Indoctrination, and Economic Prosperity in the Digital Age. IGI Global. https://doi.org/10.4018/978-1-4666-7492-9

Chua, R.Y.J., Morris, M.W., \& Mor, S. (2012). Collaborating across cultures: Cultural metacognition and affect-based trust in creative collaboration. Organizational Bebavior and Human Decision Processes, 118(2), 116-131. https://doi.org/10.1016/j.obhdp.2012.03.009

Cousins, P.D., Handfield, R.B., Lawson, B., \& Petersen, K.J. (2006). Creating supply chain relational capital: the impact of formal and informal socialization processes. Journal of Operations Management, 24(6), 851-863. https://doi.org/10.1016/j.jom.2005.08.007

Das, T.K., \& Teng, B. (1998). Between Trust and Control: Developing Confidence in Partner. Academy of Management Review, 23(3), 491-512. https://doi.org/10.5465/AMr.1998.926623

Earley, P.C. (2002). Redefining interactions across cultures and organizations: Moving forward with cultural intelligence. Research in Organizational Behavior, 24, 271-299. https://doi.org/10.1016/S0191-3085(02)24008-3

Earley, P.C., \& Ang, S. (2003). Cultural intelligence: Individual interactions across cultures. Stanford University Press, California, USA.

Earley, P.C., \& Gardner, H.K. (2005). Internal dynamics and cultural intelligence in multinational teams. In Managing multinational teams: Global perspectives (3-31). Emerald Group Publishing Limited.

Eisenberg, J., Lee, H.-J., Brück, F., Brenner, B., Claes, M.-T., Mironski, J. et al. (2013). Can business schools make students culturally competent? Effects of cross-cultural management courses on cultural intelligence. Academy of Management Learning \& Education, 12(4), 603-621. https://doi.org/10.5465/amle.2012.0022

Engardio, P., Capell, K., Carey, J., \& Hall, K. (2007). Beyond the green corporation: Imagine a world in which eco-friendly and socially responsible practices actually help a company's bottom line. It's closer than you think. Business Week, 4019, 50.

Fiske, S.T., \& Taylor, S.E. (1991). Social Cognition (McGraw-Hill series in social psychology). New York: Mcgraw-Hill Book Company.

Fornell, C., \& Larcker, D.F. (1981). Structural equation models with unobservable variables and measurement error: Algebra and statistics. Journal of Marketing Research, 18(13), 382-388. https://doi.org/10.2307/3150980 
Golini, R., Longoni, A., \& Cagliano, R. (2014). Developing sustainability in global manufacturing networks: The role of site competence on sustainability performance. International Journal of Production Economics, 147, 448-459. https://doi.org/10.1016/j.ijpe.2013.06.010

Gonçalves, G., Reis, M., Sousa, C., Santos, J. Orgambídez-Ramos, A., Scott, P. (2016). Cultural intelligence and conflict management styles. International Journal of Organizational Analysis, 24(4), 725-742. https://doi.org/10.1108/IJOA10-2015-0923

Gorondutse, A.H., \& Hilman, H. (2016). Mediation effect of organizational culture on the relationship between perceived ethics and SMEs performance. Journal of Industrial Engineering and Management, 9(2), 505. https://doi.org/10.3926/jiem.1892

Gualandris, J., Golini, R., \& Kalchschmidt, M. (2014). Do supply management and global sourcing matter for firm sustainability performance? An international study. Supply Chain Management: An International Journal, 19(3), 258-274. https://doi.org/10.1108/SCM-11-2013-0430

Hayes, A. F. (2013). Introduction to mediation, moderation, and conditionalprocess analysis: A regression-based approach . Guilford Press New York, United States.

Hair, J.F.J., Black, W.C., Babin, B.J., \& Anderson, R.E. (2010). Multivariate Data Analysis Seventh Edition Prentice Hall. USA.

Handley, S.M., \& Angst, C.M. (2015). The impact of culture on the relationship between governance and opportunism in outsourcing relationships. Strategic Management Journal, 36(9), 1412-1434.

https://doi.org/10.1002/smj.2300

Hoejmose, S., Brammer, S., \& Millington, A. (2013). An empirical examination of the relationship between business strategy and socially responsible supply chain management. International Journal of Operations \& Production Management, 33(5), 589-621. https://doi.org/10.1108/01443571311322733

Hu, L.-T., Bentler, P.M., \& Hoyle, R.H. (1995). Structural equation modeling: Concepts, issues, and applications. In Hoyle, R.H. (Ed.), Evaluating model fit. Thousand Oaks, CA, USA: Sage Publications, Inc.

Hunt, S.D., \& Morgan, R.M. (1995). The comparative advantage theory of competition. The Journal of Marketing, 1-15. https://doi.org/10.2307/1252069

Husgafvel, R., Pajunen, N., Virtanen, K., Paavola, I.-L., Päällysaho, M., Inkinen, V., et al. (2015). Social sustainability performance indicators--experiences from process industry. International Journal of Sustainable Engineering, 8(1), 1425. https://doi.org/10.1080/19397038.2014.898711

Hutchins, M.J., \& Sutherland, J.W. (2008). An exploration of measures of social sustainability and their application to supply chain decisions. Journal of Cleaner Production, 16(15), 1688-1698. https://doi.org/10.1016/j.jclepro.2008.06.001

Joshi, M.P., Das, S.R., \& Mouri, N. (2015). Antecedents of Innovativeness in Technology-Based Services (TBS): Peering into the Black Box of Entrepreneurial Orientation. Decision Sciences, 46(2), 367-402. https://doi.org/10.1111/deci.12126

Jöreskog, K.G., \& Yang, F. (1996). Nonlinear structural equation models: The Kenny-Judd model with interaction effects. In Marcoulides, G.A., \& Schumacker, R.E. (Ed.), Advanced structural equation modeling: Issues and techniques. New Jersey, USA: Hillsdale: Lawrence Erlbaum.

Klassen, R.D., \& Vereecke, A. (2012). Social issues in supply chains: Capabilities link responsibility, risk (opportunity), and performance. International Journal of Production Economics, 140(1), 103-115.

https://doi.org/10.1016/j.ijpe.2012.01.021

Kleindorfer, P.R., Singhal, K., \& Wassenhove, L.N. (2005). Sustainable operations management. Production and Operations Management, 14(4), 482-492. https://doi.org/10.1111/j.1937-5956.2005.tb00235.x

Kline, R.B. (2015). Principles and Practice of Structural Equation Modeling (4th ed.). New York, USA: Guilford Publications.

Kotabe, M., Martin, X., \& Domoto, H. (2003). Gaining from vertical partnerships: knowledge transfer, relationship duration, and supplier performance improvement in the US and Japanese automotive industries. Strategic Management Journal, 24(4), 293-316. https://doi.org/10.1002/smj.297 
Lee, S.-Y., Klassen, R.D., Furlan, A., \& Vinelli, A. (2014). The green bullwhip effect: Transferring environmental requirements along a supply chain. International Journal of Production Economics, 156, 39-51.

https://doi.org/10.1016/j.ijpe.2014.05.010

Liu, Y., Luo, Y., \& Liu, T. (2009). Governing buyer-supplier relationships through transactional and relational mechanisms: Evidence from China. Journal of Operations Management, 27(4), 294-309.

https://doi.org/10.1016/j.jom.2008.09.004

López-Duarte, C., González-Loureiro, M., Vidal-Suárez, M.M., \& González-Díaz, B. (2016). International strategic alliances and national culture: Mapping the field and developing a research agenda. Journal of World Business, 51(4), 511-524. https://doi.org/10.1016/j.jwb.2016.05.001

Lumineau, F., \& Malhotra, D. (2011). Shadow of the contract: How contract structure shapes interfirm dispute resolution. Strategic Management Journal, 32(5), 532-555. https://doi.org/10.1002/smj.890

Lusch, R.F., \& Brown, J.R. (1996). Interdependency, contracting, and relational behavior in marketing channels. Journal of Marketing, 60(4), 19-38. https://doi.org/10.2307/1251899

Luzzini, D., Brandon-Jones, E., Brandon-Jones, A., \& Spina, G. (2015). From sustainability commitment to performance: The role of intra-and inter-firm collaborative capabilities in the upstream supply chain. International Journal of Production Economics, 165, 51-63. https://doi.org/10.1016/j.ijpe.2015.03.004

Macchion, L., Moretto, A., Caniato, F., Caridi, M., Danese, P., Spina, G., et al. (2017). Improving innovation performance through environmental practices in the fashion industry: the moderating effect of internationalisation and the influence of collaboration. Production Planning and Control, 28(3), 190-201.

https://doi.org/10.1080/09537287.2016.1233361

Makri, K., Theodosiou, M., \& Katsikea, E. (2017). An empirical investigation of the antecedents and performance outcomes of export innovativeness. International Business Review, 26(4), 628-639.

https://doi.org/10.1016/j.ibustev.2016.12.004

Mani, V., Agrawal, R., \& Sharma, V. (2015). Social sustainability in the supply chain: Analysis of enablers. Management Research Review, 38(9), 1016-1042. https://doi.org/10.1108/MRR-02-2014-0037

Matanda, M.J., \& Freeman, S. (2009). Effect of perceived environmental uncertainty on exporter--importer interorganisational relationships and export performance improvement. International Business Review, 18(1), 89-107. https://doi.org/10.1016/j.ibustev.2008.12.004

Molinsky, A. (2007). Cross-cultural code-switching: The psychological challenges of adapting behavior in foreign cultural interactions. Academy of Management Review, 32(2), 622-640. https://doi.org/10.5465/AMr.2007.24351878

Moon, T. (2010). Organizational cultural intelligence: Dynamic capability perspective. Group \& Organization Management, 35(4), 456-493. https://doi.org/10.1177/1059601110378295

Naor, M., Linderman, K., \& Schroeder, R. (2010). The globalization of operations in Eastern and Western countries: Unpacking the relationship between national and organizational culture and its impact on manufacturing performance. Journal of Operations Management, 28(3), 194-205. https://doi.org/10.1016/j.jom.2009.11.001

Netemeyer, R.G., Johnston, M.W., \& Burton, S. (1990). Analysis of role conflict and role ambiguity in a structural equations framework. Journal of Applied Psychology, 75(2), 148. https://doi.org/10.1037/0021-9010.75.2.148

Ozkaya, H.E., Droge, C., Hult, G.T.M., Calantone, R., \& Ozkaya, E. (2015). Market orientation, knowledge competence, and innovation. International Journal of Research in Marketing, 32(3), 309-318.

https://doi.org/10.1016/j.ijresmar.2014.10.004

Pagell, M., \& Wu, Z. (2009). Building a more complete theory of sustainable supply chain management using case studies of 10 exemplars. Journal of Supply Chain Management, 45(2), 37-56. https://doi.org/10.1111/j.1745493X.2009.03162.x

Pahl, R.E. (1991). The search for social cohesion: from Durkheim to the European Commission. European Journal of Sociology/Archives Européennes de Sociologie, 32(2), 345-360. https://doi.org/10.1017/\$0003975600006305 
Paulraj, A., Jayaraman, V., \& Blome, C. (2014). Complementarity effect of governance mechanisms on environmental collaboration: Does it exist? International Journal of Production Research, 52(23), 6989-7006. https://doi.org/10.1080/00207543.2014.920546

Pavelin, S., \& Porter, L.A. (2008). The Corporate Social Performance Content of Innovation in the UK, 711-725. https://doi.org/10.1007/s10551-007-9464-7

Peterson, B. (2011). Cultural intelligence: A guide to working with people from other cultures. Nicholas Brealey Publishing.

Poppo, L., \& Zenger, T. (2002). Do formal contracts and relational governance function as substitutes or complements? Strategic Management Journal, 23(8), 707-725. https://doi.org/10.1002/smj.249

Preacher, K.J., \& Hayes, A.F. (2008). Asymptotic and resampling strategies for assessing and comparing indirect effects in multiple mediator models. Behavior Research Methods, 40(3), 879-891. https://doi.org/10.3758/BRM.40.3.879

Preacher, K.J., \& Kelley, K. (2011). Effect size measures for mediation models: quantitative strategies for communicating indirect effects. Psychological Methods, 16(2), 93-115. https://doi.org/10.1037/a0022658

Ribbink, D., \& Grimm, C.M. (2014). The impact of cultural differences on buyer--supplier negotiations: An experimental study. Journal of Operations Management, 32(3), 114-126. https://doi.org/10.1016/j.jom.2014.01.004

Sancha, C., Gimenez, C., \& Sierra, V. (2016). Achieving a socially responsible supply chain through assessment and collaboration. Journal of Cleaner Production, 112, 1934-1947. https://doi.org/10.1016/j.jclepro.2015.04.137

Sarkis, J., Helms, M.M., \& Hervani, A.A. (2010). Reverse logistics and social sustainability. Corporate Social Responsibility and Environmental Management, 17(6), 337-354. https://doi.org/10.1002/cst.220

Schepker, D.J., Oh, W.-Y., Martynov, A., \& Poppo, L. (2014). The many futures of contracts: Moving beyond structure and safeguarding to coordination and adaptation. Journal of Management, 40(1), 193-225.

https://doi.org/10.1177/0149206313491289

Schoenherr, T. (2009). Logistics And Supply Chain Management Applications Within A Global Context: An Overview by. Journal of Business, 30(2), 1-25. https://doi.org/10.1002/j.2158-1592.2009.tb00109.x

Sharma, S., \& Ruud, A. (2003). On the path to sustainability: integrating social dimensions into the research and practice of environmental management. Business Strategy and the Environment, 12(4), 205-214.

https://doi.org/10.1002/bse.366

Sirmon, D.G., Hitt, M.A., \& Ireland, R.D. (2007). Managing firm resources in dynamic environments to create value: Looking inside the black box. Academy of Management Review, 32(1), 273-292.

https://doi.org/10.5465/AMR.2007.23466005

Sun, P.Y.T., \& Anderson, M.H. (2010). An examination of the relationship between absorptive capacity and organizational learning, and a proposed integration. International Journal of Management Reviews, 12(2), 130-150. https://doi.org/10.1111/j.1468-2370.2008.00256.x

Tabachnick, B.G., \& Fidell, L.S. (2007). Multivariate analysis of variance and covariance. Using Multivariate Statistics, 3, 402-407.

Tan, K.H., Wong, W.P., \& Chung, L. (2016). Information and knowledge leakage in supply chain. Information Systems Frontiers, 18(3), 621-638. https://doi.org/10.1007/s10796-015-9553-6

Tavana, M., Amin, M., Di, D., \& Rahpeyma, B. (2016). A two-stage data envelopment analysis model for measuring performance in three-level supply chains. Measurement, 78, 322-333. https://doi.org/10.1016/j.measurement.2015.10.023

Teece, D., \& Pisano, G. (2004). The Dynamic Capabilities of Firms. In Holsapple, C. (Ed.) Handbook on Knowledge Management 1. Springer. https://doi.org/10.1093/icc/3.3.537-a

Tuan, L.T. (2016). From cultural intelligence to supply chain performance. The International Journal of Logistics Management, 95-121. Emerald Group Publishing Limited. https://doi.org/10.1108/IJLM-01-2014-0009

Van Dyne, L., Ang, S., \& Koh, C. (2008). Development and validation of the CQS. Handbook of Cultural Intelligence, $16-40$. 
Van Dyne, L., Ang, S., Ng, K.Y., Rockstuhl, T., Tan, M.L., \& Koh, C. (2012). Sub-dimensions of the four factor model of cultural intelligence: Expanding the conceptualization and measurement of cultural intelligence. Social and Personality Psychology Compass, 6(4), 295-313. https://doi.org/10.1111/j.1751-9004.2012.00429.x

Vilana, J.R., \& Monroy, C.R. (2010). Influence of cultural mechanisms on horizontal inter-firm collaborations. Journal of Industrial Engineering and Management, 3(1), 138-175.

Weerawardena, J., Mort, G.S., Liesch, P.W., \& Knight, G. (2007). Conceptualizing accelerated internationalization in the born global firm: A dynamic capabilities perspective. Journal of World Business, 42(3), 294-306. https://doi.org/10.1016/j.jwb.2007.04.004

Zhou, K.Z., Zhang, Q., Sheng, S., Xie, E., \& Bao, Y. (2014). Are relational ties always good for knowledge acquisition? Buyer-supplier exchanges in China. Journal of Operations Management, 32(3), 88-98. https://doi.org/10.1016/j.jom.2014.01.001

Zorzini, M., Hendry, L.C., Huq, F.A., \& Stevenson, M. (2015). Socially responsible sourcing: reviewing the literature and its use of theory. International Journal of Operations \& Production Management, 35(1), 60-109. https://doi.org/10.1108/IJOPM-07-2013-0355 


\section{Appendix A}

\begin{tabular}{|c|c|}
\hline \multicolumn{2}{|c|}{ Scale Items } \\
\hline \multicolumn{2}{|c|}{$\begin{array}{l}\text { Relational Governance (RG): measured to what degree do you agree or disagree the following statements about on a 7-point } \\
\text { scale ( } 1 \text { - Strongly disagree, } 7 \text { - Strongly agree) }\end{array}$} \\
\hline RG1 & Our customer is involved early in the development of social initiatives. \\
\hline RG2 & $\begin{array}{l}\text { Our firm has the mutual understanding of how to carry out solutions for failure in the protection of social } \\
\text { issues. }\end{array}$ \\
\hline RG3 & $\begin{array}{l}\text { Our firm has the mutual understanding of how to settle down issues with our customer on social protection } \\
\text { of our workers }\end{array}$ \\
\hline RG4 & $\begin{array}{l}\text { Our firm has the mutual understanding with customers the actions to be carried out when there are accidents } \\
\text { at worker place. }\end{array}$ \\
\hline \multicolumn{2}{|c|}{$\begin{array}{l}\text { Social Performance (Cronbach's alpha }=0.0 .819) \\
\text { 1: not at all, 2: a limited extent, 3: slightly improve, }\end{array}$} \\
\hline SSP1 & We have reduced the number of industrial accidents. \\
\hline SSP2 & We have improved child labor employeement in our facilities. \\
\hline SSP3 & We have improved employee level of satisfaction with policies (social security systems, job security). \\
\hline SSP4 & We have improved safety and labor conditions in our facilities \\
\hline \multicolumn{2}{|c|}{$\begin{array}{l}\text { Innovation Performance }(\text { Cronbach's alpha }=0.778) \\
\text { 1: Strongly disagree, 2: Disagree, 3: Somewhat disagree, 4: Neither agree or disagree Agree, 5: Somewhat agree, 6: Agree, } \\
\text { 7: Strongly agree }\end{array}$} \\
\hline IPF1 & Process design \\
\hline IPF2 & Product design \\
\hline IPF3 & Ability to conformances to specification \\
\hline IPF4 & Ability to develop new products \\
\hline \multicolumn{2}{|c|}{$\begin{array}{l}\text { Cultural Intelligence (CQ), measured to what degree do you agree or disagree the following statements about on a } 7 \text {-point } \\
\text { scale (1 - Strongly disagree, } 7 \text {-Strongly agree) }\end{array}$} \\
\hline \multicolumn{2}{|c|}{ Meta cognitive } \\
\hline MEQ1 & $\begin{array}{l}\text { We are conscious of the cultural knowledge, we use when interacting with people with different cultural } \\
\text { backgrounds. }\end{array}$ \\
\hline MEQ2 & We adjust our cultural knowledge as we interact with people from a culture that is unfamiliar to me \\
\hline MEQ3 & We check the accuracy of our cultural knowledge as we interact with people from different cultures \\
\hline MEQ 4 & We are conscious of the cultural knowledge I apply to cross-cultural interactions (Deleted) \\
\hline \multicolumn{2}{|c|}{ Cognitive } \\
\hline COQ1 & We are aware of the cultural values and religious beliefs of other cultures \\
\hline COQ2 & We are aware of the legal and economic systems of other cultures \\
\hline COQ3 & We are aware of the rules for expressing nonverbal behavior in other cultures \\
\hline
\end{tabular}

Journal of Industrial Engineering and Management, 2018 (www.jiem.org)

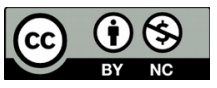

Article's contents are provided on an Attribution-Non Commercial 4.0 Creative commons International License. Readers are allowed to copy, distribute and communicate article's contents, provided the author's and Journal of Industrial Engineering and Management's names are included. It must not be used for commercial purposes. To see the complete license contents, please visit https://creativecommons.org/licenses/by-nc/4.0/. 